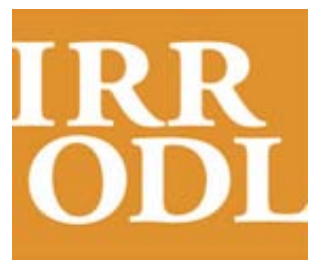

International

Review of

Research in Open

and Distance

Learning

Vol. 12.3

March - 2011

\section{EduCamp Colombia: Social Networked Learning for Teacher Training}

\author{
Diego Ernesto Leal Fonseca \\ EAFIT University, Columbia
}

\begin{abstract}
This paper describes a learning experience called EduCamp, which was launched by the Ministry of Education of Colombia in 2007, based on emerging concepts such as e-Learning 2.0, connectivism, and personal learning environments. An EduCamp proposes an unstructured collective learning experience, which intends to make palpable the possibilities of social software tools in learning and interaction processes while demonstrating face-to-face organizational forms that reflect social networked learning ideas. The experience opens new perspectives for the design of technology training workshops and for the development of lifelong learning experiences.
\end{abstract}

Keywords: EduCamp; connectivism; personal learning environments; e-learning 2.0; unconferences

\title{
Introduction
}

If you imagine a workshop on the use of information technology aimed at teachers or anyone else, a recurring image will be that of computers arranged in rows, all facing the same direction, with a facilitator at the front indicating to participants the steps they are to take. This arrangement reflects the typical organization of a classroom, and even when there are laptops available, it is common to organize participants so they look straight ahead or toward wherever the expert might be. It can be argued that such a spatial disposition reflects a logic of scarcity and information transmission that lies behind the way we think about many of our physical spaces and educational activities (both face-to-face and online), including workshops for the use of information and communication technologies (ICTs).

Emerging opportunities made possible by new technologies have, so far, changed very little about the technology training programs offered to teachers. Although technology is used, the 
image of the teacher as an expert who not only decides what makes sense to learn, but also has the final word (through evaluation) on whether someone has learned remains dominant. The learner remains, in most cases, a consumer of the information the teacher deems appropriate. In fact, Benavides and Pedró (2007) go beyond this observation to conclude that in Iberoamerica there is nothing to indicate that ICT use has achieved "a revolution in pedagogical models, which still do not embody the paradigm required by a knowledge society.”

These observations were the starting point for a series of experiences developed by the Office for the Promotion of Higher Education at the Ministry of Education of Colombia, aimed at exploring opportunities and alternative scenarios for helping higher education teachers to discover new ways of using ICT in their practice.

During the second semester of 2007, a series of workshops on the use of social software tools was designed and implemented. These workshops, called EduCamps, modeled a face-to-face social networked learning space in which several emerging concepts (such as e-Learning 2.0 and personal learning environments, or PLEs) were brought into play. EduCamps were intended to enable a different learning environment, directly related to the possibilities of current technologies, in which individual responsibility in the use of ICTs was made evident, as well as the need to consider how (and when) to distribute the role of the expert among a community of learners. So far, over 1,000 teachers in seven cities nationwide have attended the workshops.

This experience suggests that, for some teachers, a change in their perception about technology use can be achieved through activities that confront their deepest convictions about what it means to learn and teach, allowing them to discover themselves as apprentices in a continuous process and as members of a larger community to which they can turn for answers.

\section{Background}

\section{The Origin of the EduCamp}

The Vice Ministry of Higher Education of Colombia, through the Office for the Promotion of Higher Education, launched an ambitious project in 2004 to foster the development of different aspects of the integration of ICT in Colombian higher education institutions. An important part of this project was focused on the use and adoption of media and ICT, and several strategies to enable the adoption of emerging technologies and methodologies were developed.

Starting in 2005, several teacher and administrator training programs were offered nationwide. These included, for instance, three-day workshops aimed at university provosts and online courses on virtual learning environment design and facilitation aimed at higher education teachers. Also, an online community for teachers was created, and several international seminars were organized.

The international seminar held in 2007 discussed emerging concepts such as e-Learning 2.0, personal learning environments, and informal learning, and it posed the challenge of introducing 
these ideas and their implications for the design of learning environments to higher education teachers. However, it was not clear whether the existing online courses would be the most effective way to communicate these ideas. Also, these courses were focused on the development of fully online learning environments, while most teachers were involved in blended learning scenarios. Therefore, there was a window of opportunity to offer complementary training alternatives.

The original idea of the EduCamp workshops emerged from conversations with Nancy White, Jay Cross, and Fernando Diaz del Castillo (at the time, the person in charge of the use and adoption of ICT for Basic Education at the Ministry of Education). Brainstorming took place in August, 2007 about how to design an experience to facilitate what White called "over-theshoulder” learning (White, 2007).

"Over-the-shoulder" learning is a fairly common practice in software development training, where students share solutions to specific problems as they appear, working side by side, generating a relationship different from that seen in a typical classroom. It is recognized that any one can act as an expert in a specific area (the use of a tool, for example) and that knowledge is not exclusively transmitted from one to many (teacher to students), but also can be transmitted among unstructured groups of people. "Over-the-shoulder" learning would be, in fact, an example of what Bandura (1986) described as vicarious learning, with modeling playing a fundamental role in the process.

So the question was how to enable technology adoption processes for teachers, based on "overthe-shoulder” learning and in an environment that reflected some of the emerging concepts mentioned earlier. It was not enough to talk about the possibilities of technology. Rather, it was essential to make them visible and to model them for all attendees. With these thoughts in mind, a full-day workshop was designed, mixing several techniques of individual and collective work. It was presented as a "workshop on the use of social software tools" and designed to be offered to about 100 people at once.

\section{The Concepts Embedded in the Design}

The workshops were focused on exploring the use of a broad set of social software tools, articulated around the characterization and enhancement of the personal learning environment (PLE) of each participant, a concept whose first documented appearance corresponds to a workshop held by the UK’s Joint Information Systems Committee (JISC) in November, 2004 (Wikipedia contributors, 2009).

Interestingly, the notion of a PLE does not yet have a precise definition in the academic community (Trafford, 2006). In some cases, it is an essentially technological approach (Downes, 2005; e-Framework, 2005; Wilson, 2005; Harmelen, 2006), appearing as an alternative to the concept of the virtual learning environment (and hence the so-called learning management systems, or LMSs) (Anderson, 2007; Wilson et al., 2007; Hand, 2007); in others, it is recognized (and displayed) as a map that shows the environment in which a person learns (Leslie, 2008b). 
In the latter case, a PLE diagram may include, with more or less detail, the physical spaces in which people learn, the people from whom or with whom learning happens (teachers, mentors, colleagues, other learners), the media used to access relevant information (textbooks, academic articles, television, radio, newspapers, blogs, wikis, mailing lists, etc.), and the tools used to compile that information or to interact with others (including, usually, a variety of social software tools). This is the approach used in an EduCamp.

The components of a PLE vary from person to person, as do their relative importance. More than an application or computer platform, a PLE is composed of people, spaces, resources, and tools that are interrelated and that interact in different ways depending on the habits and needs of each person.

There was an interest in getting participants to experience different forms of organization for collective work, enabling each learner to discover and explore his or her interests using technology, outside of a curriculum and objectives predetermined by others. For this reason, the design of the workshop was based on several techniques used to carry out unconferences.

An unconference relies on minimal structure, allowing participants to decide the issues to be addressed within a broader subject area. Given that many unconference techniques come, in fact, from more established methodologies of conversation, some of these techniques were explored. The workshop made use of ideas from Open Space Technology (see http://www.openspaceworld.org/), The World Café (Brown \& Isaacs, 2005), BarCamp (see http://www.barcamp.org/), PodCamp (see http://podcamp.pbworks.com/), Pecha Kucha (see http://www.pecha-kucha.org/), and even an approach called Speed Geeking (see http://facilitation.aspirationtech.org/index.php/Facilitation:SpeedGeeking). The name Educamp itself comes, in part, from unconferences having the suffix camp in their names (FooCamp, BarCamp, PodCamp, etc.), but with an educational emphasis.

The workshops were designed with a defined yet flexible structure, which brings together several concepts and has a specific interest in the adoption of social software tools. They were not designed as a BarCamp, whose discussions are related to education (as can be seen in other experiences called educamps; see http://educamp.pbworks.com/).

It is important to note that, to the author's knowledge, back in 2007, there were no documented training experiences specifically related to personal learning environments, even though there have been courses and workshops related to the use of social software tools for several years now. In 2008, some workshops that focused on the development of personal learning environments started to appear (see Leslie, 2008c and Gray, 2009, for example), as well as online resources related to the building of personal learning networks (Waters, 2008). This means the original 2007 design of EduCamp was not influenced by other experiences in the area. 


\section{The Structure of an EduCamp}

\section{Identifying the PLE}

The workshop began with a check-in, at which each participant received a laptop computer to use throughout the day. In all cases, the logistics team of the Ministry of Education leased the computer equipment, given that most Colombian teachers did not own laptops.

A sheet listing software tools was provided as reference material. It contained general descriptions of various categories of tools, including picture, audio, video, and document publishing and sharing, as well as platforms for social bookmarking, blogs, wikis, RSS

aggregators, and social networks, among others. Each category included links to some of the web applications available. The sheet has since evolved to include guiding questions for the characterization and expansion of the PLE for each participant, and a white outline on the back, in which each person can draw his or her own PLE (see Figure 1).
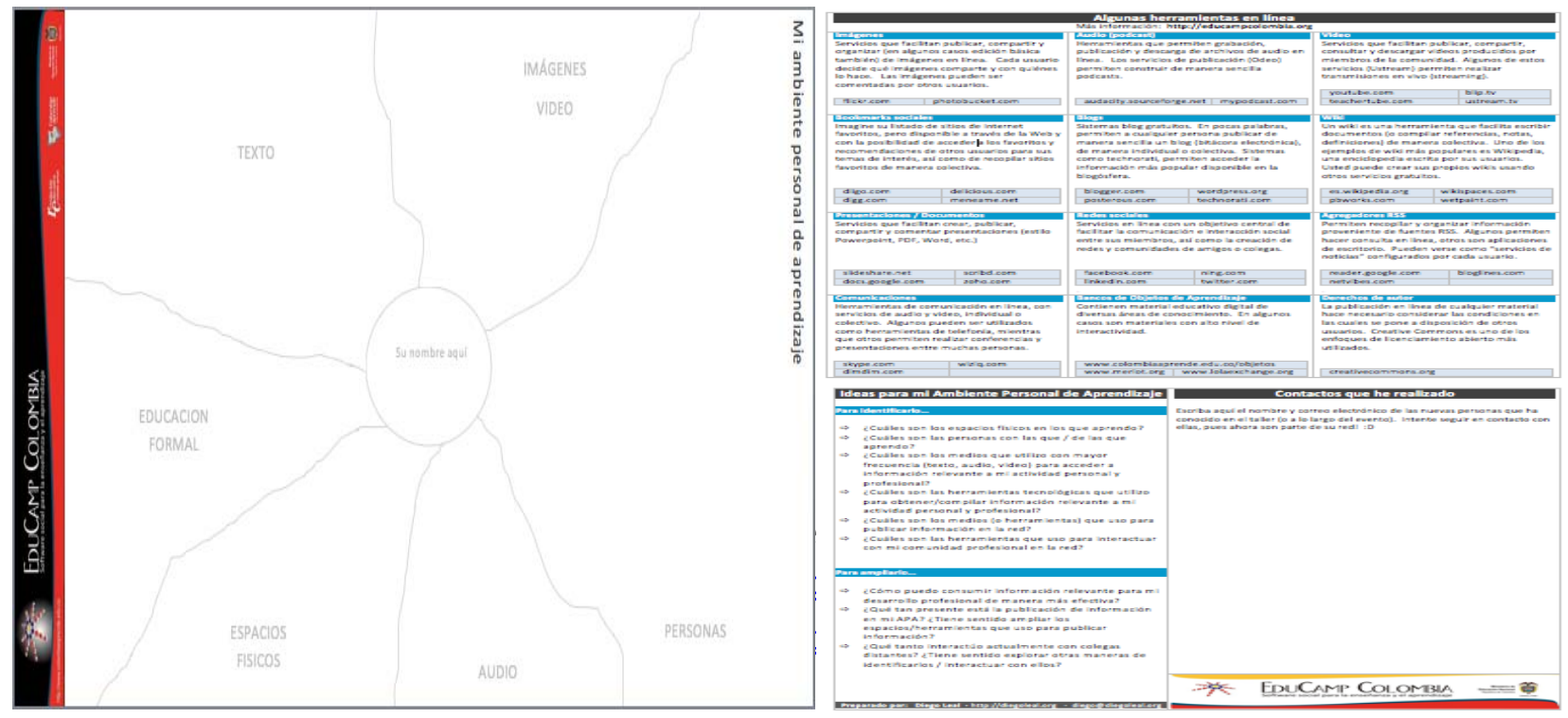

Figure 1. Facsimile of the PLE outline and the tool sheet (Available in Spanish at http://www.scribd.com/doc/8325751/Ambiente-Personal-de-Aprendizaje and http://www.scribd.com/doc/19330108/Hoja-de-Apoyo-EduCamp ).

The session started with an initial introduction of the participants, using chat tools such as Chatterous to facilitate the quick collection of information. This activity helped to identify both technical network problems, as well as the attendees' skills in the use of technology. In addition, it represented an opportunity to encourage the more skilled attendees to help those who were having problems.

The chat was presented as the workshop backchannel, a space to discuss both presentations and activities during the day. While in other events the backchannel is often articulated through the use of specific tags on platforms such as Twitter, the diversity of this workshop's participants 
(who may not have known what Twitter is) made it imperative to select a tool closer to the previous experiences of most attendees (a chat).

After a presentation of the context of the workshop and some ground rules, the basic ideas related to the concept of a personal learning environment were presented. The discussion included the usefulness of its characterization and the relationship it has with social software, referring to the definition presented earlier in this document.

Then each participant characterized the current state of his or her PLE in the way he or she saw fit (list, diagram, graph, etc.), using as guides the tool sheet and some questions proposed. These questions led to an analysis of the physical spaces in which each person learned, the people with or from whom he or she learned, and the media (text, audio, video) most frequently used to access information relevant to personal and professional activities, as well as the technological tools used to obtain and compile that information. Also, participants identified the media and tools used to publish information and the tools they used to interact with their professional community on the Web.

Given that the elements of a PLE change from one person to the next, this exercise usually turns into a personal reflection, where there are no right or wrong answers but simply opportunities for growth. Starting in 2008, even though the PLE sheet contained an initial scheme, participants had the freedom to use a scheme relevant to each individual case from a series of diagrams compiled by Scott Leslie (Leslie, 2008a).

An important part of PLE characterization is to identify the technological tools that are part of the PLE, so the workshop participants used the descriptions and links included in the tool sheet as a guide. Then everyone wrote the names of any social software tools that were part of their PLE (even those not included in the tool sheet) on stickers handed out at the beginning, which they stuck to their clothes (see Figure 2). This tagging exercise had two purposes: one, to familiarize participants with the concept of labelling resources, and two, to make visible to others those tools that each participant knew. 


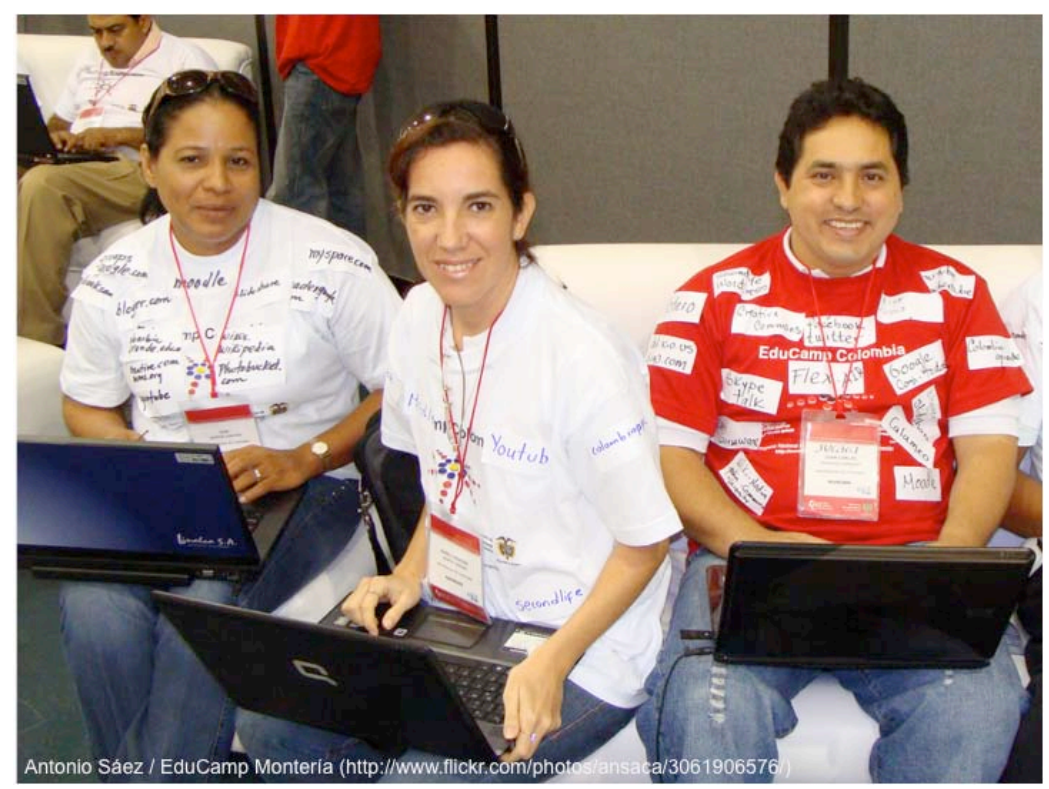

Figure 2. Participants with tags on their clothing.

\section{Expanding the PLE}

During the final part of the first exercise, participants identified on their tool sheet those tools that could expand or enrich their PLE, depending on their personal needs. Starting in 2009, the tool sheet included some guiding questions to address this process, such as how information relevant to professional development can be accessed more effectively and whether it made sense to broaden the opportunities/tools used to publish information online. Other considerations included the analysis of the current level of interaction with distant colleagues and whether it made sense to explore new ways to identify and interact with them.

It is worth noting that this exercise helped participants to think about the environment in which they learned, making visible that such activity happens not only in formal spaces. The PLE diagram showed information consumption trends that were unnoticed by them, as well as opportunities for growth based on personal needs.

Based on the set of available tools, each learner selected those he or she wanted to learn. To that extent, the role of the expert in charge of defining what was to be learned disappeared, and control over this specific curriculum (if I can refer to it in such a way) was transferred to the learners.

With this roadmap, participants worked on the expansion of their PLE, using as an input the stickers representing those social software tools that each person knew and the tool sheet showing the tools each person wanted to learn about. Participants became involved in a collective searching and learning process with the support of other participants, not just with an "expert instructor." 
The stickers were critical because the presence of a sticker meant that whoever was wearing it knew about a specific tool. Thus, the first step in the learning process was to find others who had stickers related to the learner's personal interests. In this sense, the first step of the activity brought into play an assertion made by Siemens (2006, p. 32): “'Know where' and 'know who' is more important today than knowing what and how."

One rule for this stage stated, "If someone approaches you to learn about a tool, you are obliged to help.” Thus, once learners identified potential teachers, it was just a question of saying hello and asking for information about the tool of interest. It is worth noting that, in an auditorium with 100 strangers, this became a great excuse to strike up conversations and create new contact networks.

Taking advantage of the fact that each participant had a laptop with a wireless connection, the expert explained and showed the apprentice how the selected tool worked, helping him or her to explore it and subscribe to it, using his or her own computer. Given that most of the selected tools allow the publication of material almost immediately, at the end of each consultancy, the learner would leave with an additional subscription to the tool he or she wanted to explore and, ideally, with some form of material published online. The apprentice was then invited to add a new tag to his or her clothing as a way of making visible the learning achieved. Also, participants had the opportunity to explore on their own, using the information provided at the beginning, and several stations addressing different tools were put in place so that each person could choose among different learning alternatives.

This activity challenged the idea that it is essential for everyone to cover the same curriculum in the same time frame, as well as the notion that it is possible to learn everything about a topic. In the workshops, learning was modeled as a complex, messy, social process, completely dependent on the context (external and internal), features that made the methodology very close to cognitive and constructivist principles.

\section{Talking about Opportunities and Challenges}

After working on the expansion of their PLE for a couple of hours, participants were invited to brainstorm about how the tools explored could be used in their personal and professional practice. This collective inventory of affordances sought to give a broader meaning to the expansion of each PLE. Depending on the available space and number of attendees, several stations (i.e., discussion tables, one for each tool category included in the tool sheet) were arranged for small-group discussions. At each station, someone assumed the role of reporter.

Once the participants were distributed at the different stations, they began five-minute brainstorming sessions about the educational affordances of the tool assigned to that station. Upon completion of a five-minute session, participants (except the reporters) went to the next table to repeat the exercise with a new tool. 
Each reporter took notes of the ideas generated at each station, which were then posted on a wiki. At the end of this activity, the contributions made by all participants during their transit through the different stations were collected.

Using this design of distributed brainstorming, attendees covered 12 different tools in just one hour, listening both to the ideas of their peers and the additional ideas recorded by the groups that preceded them. Additionally, there was a public record of the activity, available for future reference.

As mentioned above, one of the intentions of the workshops was to expose participants to several types of collective learning methodologies that would enable them to discover new possibilities for their daily practice. For this reason, after the brainstorming session, participants had the option of experimenting with a short unconference.

Using the stations from the previous part of the workshop, participants were invited to lead and participate in half-hour group discussions. Each table had a reporter, who recorded the most important points of the conversation.

The discussion topics were proposed throughout the day, using an idea from Open Space Technology: a large board was put in place with two half-hour slots in which attendees could propose, at any time of the day, their discussion topics around a global issue (the challenges associated with the use of social software tools, for example). In 2008, instead of a board, a computer was used to record and display the discussion topics.

During this segment of the workshop, a variation of the "rule of two feet" (also from Open Space Technology) was stated: "If you are not learning or participating in a discussion, please use your two feet and go to another one.” This message was a reminder to all participants to be where they wanted to be. At the end of the half-hour discussion, one person per table reported some of the partial conclusions to the whole group.

The last part of the workshop was focused on a personal reflection on what each participant had learned. An online survey was used, which included questions that explored specific aspects of the organization, activities, dynamics, and facilitation of the workshop.

The survey invited participants to reflect on what they had learned, what they would have liked to have learned, the immediate actions to perform with the things learned, and whether they would recommend the workshop to someone else.

This activity led to a collective reflection in which the facilitator went back to the principles proposed at the beginning of the day, anchoring them in the experience lived, emphasizing the importance of understanding the workshop as a starting point along a road on which we are all learners and where we each need, in the words of Gandhi, to "be the change you want to see in the world.” 


\section{A Word on Physical Space}

The workshop included activities that created new opportunities for interaction among participants. An equally important aspect was the space in which these activities were carried out: an unstructured, disorganized space that, along with the furniture used, conveyed a clear and positive message about the nature of the activity developed throughout the day (see Figure 3).

This aspect was the first un-structuring element, because the attendees came to a workshop on technology and discovered an informal and flexible environment, which was integral to the activities taking place. It is worth noting that the level of un-structure of the space depends largely on local conditions. (For a more detailed discussion on this topic, see Leal, 2010.)

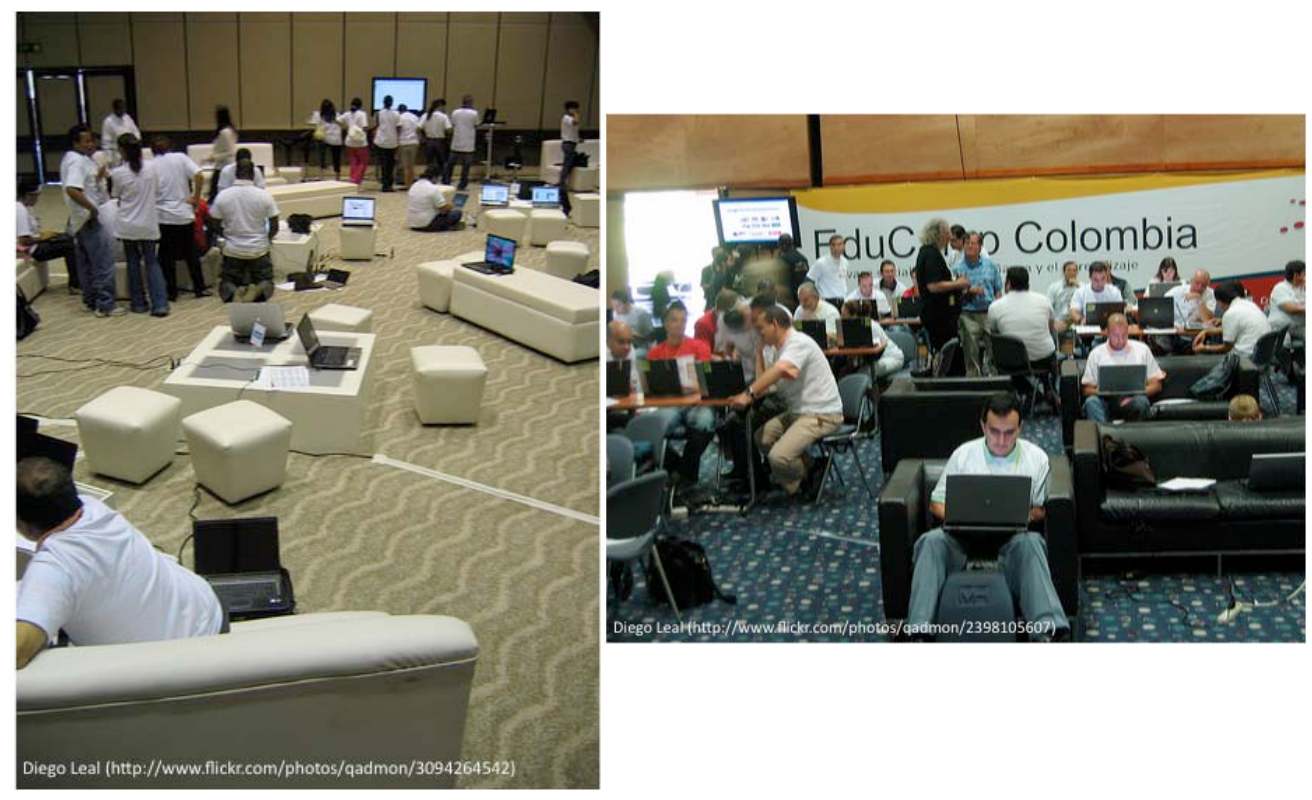

Figure 3. Examples of furniture and space.

An EduCamp requires good Internet connectivity. This is a critical aspect for the workshop because an inoperative network has negative effects on the experience of participants. It is interesting to note that the setup (about 100 laptops connected all day long) was challenging in most of the venues where the workshops took place. In this way, the workshops actually helped to test the infrastructure conditions for this kind of event around the country.

It is also important to consider the convenience of wireless versus fixed connections. Two factors are involved: mobility and reliability. Fixed connections mean less mobility but usually higher reliability. This does not mean that a wireless connection is unreliable, just that support for fixed connections for such a high number of people is a more complex demand.

Finally, music was incorporated into the environment in all workshops. Sometimes it was used as a background for activities; sometimes it was used as an indicator of changes that were part of the dynamics of the workshop. Music served to energize or relax the atmosphere. 


\section{An Experiment that Grows}

The initial experiment was conducted in the cities of Bogotá and Medellín in December, 2007, including over 100 attendees in each city. In 2008, additional workshops were added, reaching seven cities: Bogotá, Monteria, Pereira, and Cartagena during the last week of November, and Bucaramanga, Medellín, and Cali during the second week of December. Although a very welldefined structure for the workshops was in place, different auditoriums and targets led to continuous experimentation to adapt the EduCamp to multiple settings.

In 2008, a group of people was coached to act as workshop facilitators. Some of these new facilitators, as well as several participants, later decided to take the experience to their own institutions, adapting it to their specific context. To date, at least 12 Colombian higher education institutions have held EduCamps in their own spaces, using their own resources, led by people who have found such great value in the experience as to attempt to replicate it. Also, workshops based on these ideas have been held in Mexico and Argentina, and there have been experiences with primary education teachers, Ministry of Education staff, and even secondary school students.

The duration of the workshops has varied, from eight hours in 2007 and 2008 to six, four, and even three hours in 2009. Clearly, this means that not all activities can be developed and that the outcomes of the experience vary accordingly. The infrastructure used through 2009 has also been diverse, with desktop computers arranged in rows or along the perimeter of a room with fixed network connections. From these experiments, it is clear that the unstructured environment has a great impact on the attendees' perception of the learning experience.

Given that hosting an EduCamp is not an easy task, its voluntary multiplication is an unexpected and happy situation. Many other participants have transferred what they learned during the experience to their personal and professional spaces, changing elements of their teaching and initiating processes to strengthen their online presence.

Since 2008, the results of the activities developed in the EduCamps have been compiled in a wiki (see http://educampcolombia.org), where it is possible to obtain information about the different tools explored in the workshop, its methodology, and the resources used. This information is published under a Creative Commons license of attribution, non-commercial use and share alike, which turns it into an open educational resource. Ning spaces have also been created, aimed at fostering discussion about methodology issues among facilitators of the workshop (see http://educampcolombia.ning.com). While these spaces are still incipient, they represent a toolbox for new people to bring this kind of experience into their own environments, representing a latent opportunity in terms of testing new configurations for the workshops. 


\section{Discussion}

\section{Analysis of the Concepts behind the Workshops}

It is important to emphasize that the relation between theory and practice, in this case, began to surface after the workshops were done. While it is clear that there are certain theoretical bases to which the workshops respond, originally they were designed pragmatically to solve specific problems, rather than responding to the postulates of a specific theory or the indications of a given methodology.

Therefore, although it is possible to find relations to specific techniques, methods, or theories, the workshops did not intend to represent a determined theoretical position. It can be argued that there is a clear relation here with what Siemens suggests in his book Knowing Knowledge about the importance of doing (2006, p. 124; emphasis in original):

The pragmatics of implementation is important in our society today. The days of academic theorizing no longer exist outside of implementation. The work of the philosopher gave way to the scientist. The work of the scientist is giving way to the DOER.

This means that the following account is necessarily incomplete, and perhaps the reader will be able to identify new patterns and relationships that are not covered in this analysis.

The EduCamp reflects some of the ideas on connectivism and connective knowledge proposed by George Siemens and Stephen Downes. A strong catalyst for the workshops was the ideas expressed by Stephen Downes in his article "E-Learning 2.0" (Downes, 2005), as well as the presentation made on this subject by Graham Attwell at an international seminar held in Bogotá in 2007 (Attwell, 2007). The key design element for the EduCamps, that of encouraging collaborative practices among strangers in an environment that allows them to discover that everyone can be teacher and learner at the same time, coincides with several elements of the ideas of Siemens and Downes.

Throughout the workshop there are neural connections created that reflect the external social network, for example, "I learned about this tool with this person." In this sense, the EduCamp implements some connectivist ideas, especially those related to diversity of opinion, the connection of specialized information sources, and decision-making. In fact, what Siemens calls the "epitome of connectivism" is an adequate description of the activity to which participants are exposed: the "amplification of learning, knowledge, and understanding through the extension of a personal network" (Siemens, 2004). This amplification was not restricted to knowing a set of tools; it was complemented with the exploration of their possibilities and potential problems.

In addition, the EduCamp acknowledges learning as chaotic, continuous, and complex, made possible by co-creation and connected specialization. Additionally, it recognizes the impossibility of having certainty, accepting uncertainty and ambiguity as essential and 
unavoidable aspects of the process. All these elements are part of the way Siemens defines learning (2006, p. 39). Now, it is only fair to note that this is possible, in part, because the workshop is an informal space, which does not depend on evaluation or certification by an institution. It is an open question whether similar effects can be achieved in formal environments.

The strategy adopted by the workshop also reflects some characteristics of a network of connective knowledge, referred to by Downes as "semantic condition" (2006). The workshop

- depends on diversity in knowledge, expertise, and application;

- delivers a high level of autonomy to learners, who act according to their own values and decisions;

- encourages greater interactivity among a number of people (and, it could be argued, helps to expand the social network of participants, creating new bonds, taking advantage of weak ties and strengthening existing ones);

- fosters openness among participants, allowing the entry of any perspective, without disqualifying any in advance.

The role of the participants mirrors the expected role of a learner in what is proposed by Downes as a possible network pedagogy (Downes, 2006): They are part of an authentic environment, are involved in observation and emulation of good practices, and engage in conversations about practice. It is somewhat difficult to talk about the role of the facilitator, which certainly is different from that expected in a longer educational process. However, the elements of transparent work (modeling and demonstration) mentioned by Downes are visible, as is the involvement in network activity.

Nevertheless, it is worth saying that the role of the teacher is actually distributed among all the participants in the workshop. In this sense, the ideas of Cormier (2008) concerning a rhizomatic model of education can be linked as well to the EduCamps:

In the rhizomatic model of learning, curriculum is not driven by predefined inputs from experts; it is constructed and negotiated in real time by the contributions of those engaged in the learning process. This community acts as the curriculum, spontaneously shaping, constructing, and reconstructing itself and the subject of its learning in the same way that the rhizome responds to changing environmental conditions.

As mentioned earlier, the identification of these ideas was a process subsequent to design and implementation. Arguably, the workshops resemble or reflect some of those ideas, but it is important to clarify once again that they were not included explicitly in their design. 


\section{Results and Perspectives}

So far, about 1,054 people have participated in the workshops. Since 2007, different surveys have been used to collect the perceptions of participants, reaching over 620 people (about 59\%), as seen in Table 1.

Table 1

Summary of Answers Included in the EduCamp Survey

\begin{tabular}{|c|c|c|c|c|c|c|c|}
\hline & Bad & Average & Acceptable & Good & Excellent & $N / A$ & $N$ \\
\hline $\begin{array}{l}1 . \text { Did the workshop meet } \\
\text { your needs and expectations? }\end{array}$ & 3 & 2 & 29 & 201 & 392 & 2 & 629 \\
\hline $\begin{array}{l}\text { 2. Did the proposed activities } \\
\text { allow you to reach your } \\
\text { goals? }\end{array}$ & 1 & 3 & 29 & 228 & 365 & 3 & 629 \\
\hline $\begin{array}{l}\text { 3. Is there practical } \\
\text { application for the things } \\
\text { learned in the workshop? }\end{array}$ & 2 & 7 & 44 & 158 & 207 & 2 & 420 \\
\hline $\begin{array}{l}\text { 4. How efficient were the } \\
\text { strategies used? }\end{array}$ & 2 & 10 & 64 & 204 & 344 & 5 & 629 \\
\hline $\begin{array}{l}\text { 5. Was facilitation } \\
\text { appropriate? }\end{array}$ & 0 & 7 & 33 & 192 & 386 & 11 & 629 \\
\hline $\begin{array}{l}6 . \text { Did the workshop } \\
\text { structure/organization meet } \\
\text { your expectations? }\end{array}$ & 0 & 11 & 45 & 208 & 356 & 9 & 629 \\
\hline $\begin{array}{l}\text { 7. Was the time available } \\
\text { enough for the activities } \\
\text { proposed? }\end{array}$ & 1 & 19 & 88 & 168 & 139 & 5 & 420 \\
\hline
\end{tabular}

When asked whether the workshop met their needs and expectations, 62\% of the respondents qualified the experience as "Excellent" and 32\% as "Good." This pattern is seen in other aspects of the survey, where an "Excellent" rating was selected in over 50\% of all cases, and the combination of "Good" and "Excellent" was consistently over 85\%. It is worth noting that questions 3 and 7 were not included in all the surveys.

One of the most common themes in the comments registered was related to the time available. For most participants, there was not enough time to explore all the tools. This was expected 
given the number of software tools, but could also be explained by participants' pre-conceived notions regarding the learning expected in formal environments: Learn all you have to learn (in our case, that would be all the tools included in the tool sheet) in a fixed time.

The survey also included open-ended questions exploring several subjects (see Figure 4). One of them had to do with the most important thing learned in the workshop. Nearly one quarter (24\%) of participants highlighted the opportunity of learning specific tools, with blogs, YouTube, and Second Life the most frequently mentioned. Also, 22\% pointed out the pedagogical and learning possibilities of many of these tools, which were initially perceived as essentially social.

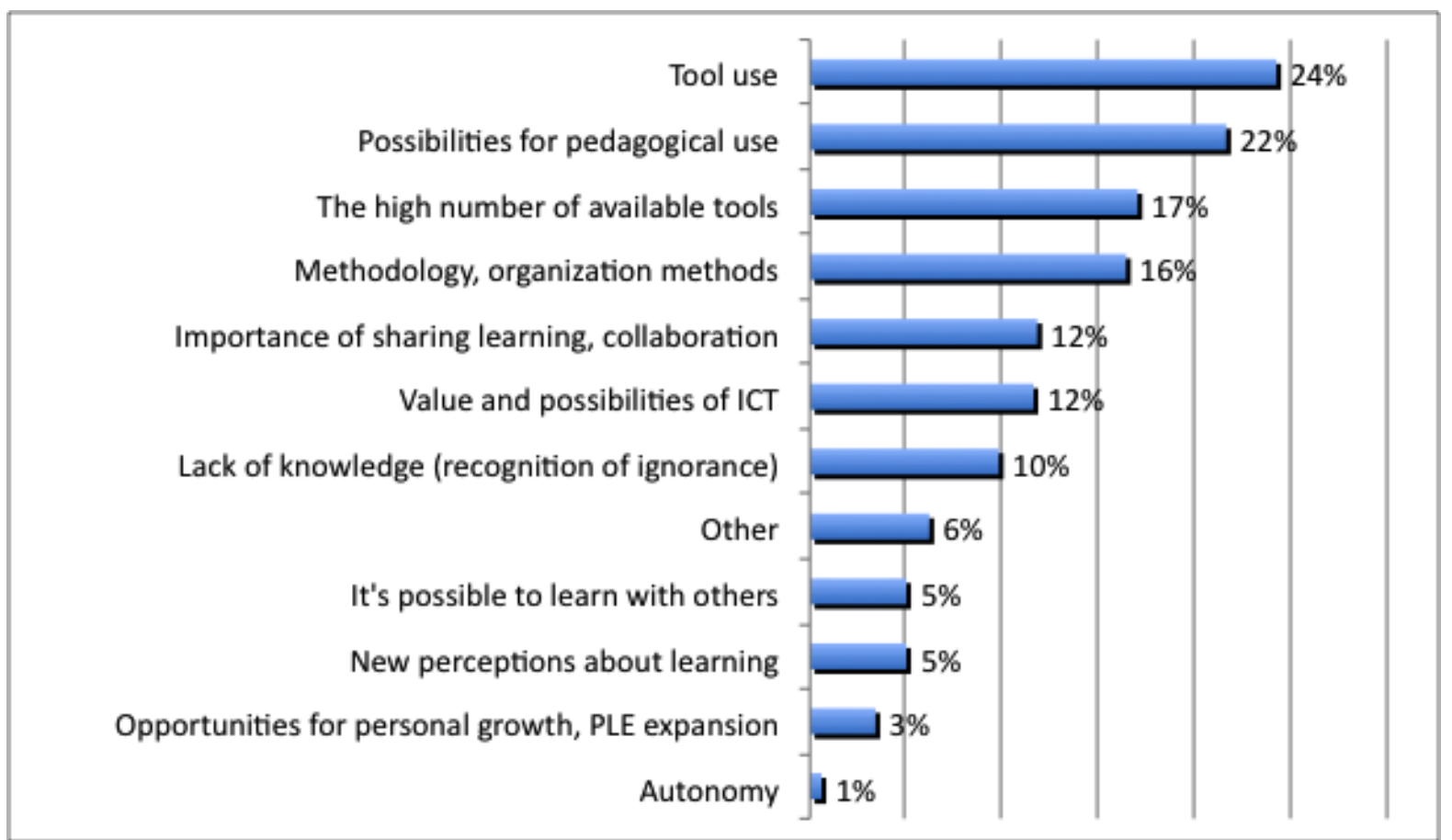

Figure 4. Answers to the question "What was the most important thing you learned in the workshop?”

On the other hand, 17\% expressed their surprise at the huge number of available tools and the importance of now being aware of their existence, while $16 \%$ mentioned the methodology as the most important thing learned during the workshop, focusing on the different forms of group organization and the importance of sharing and learning with/from others.

In addition, $12 \%$ expressed a new perception of the value and possibilities of ICT in their personal lives, and only 5\% mentioned new perceptions about the nature of learning and the role of the learner in a networked world.

Finally, it is worth mentioning that $10 \%$ of participants expressed recognition of how little they knew about this area and of the need to continue with the exploration and adoption of these tools. 
These comments suggest that the experiment was successful not only in terms of its objectives, but that such a proposal could represent a real alternative to more traditional training programs in terms of transformation of attitudes about the role of technology in learning processes. However, it is important to point out the low number of explicit answers related to new perceptions about learning (5\%) and autonomy (1\%), something that is central to the design of the workshops. Even though some of the other answers can be related to these two subjects, few people recognize them directly.

One of the most interesting (yet anecdotal) comments came from the first workshops done in Medellín in 2007. This attendee said

I have never learned so much in so little time. I thought that learning about blogs or Flickr (I didn't even know how they were used) would cost me much time and training and an impressive investment... I can't wait to get home to practise all of this...

It is important to note a few things that could bias the survey results: 160 people experienced a shorter version of the workshop, which means that they did not have enough time to develop some of the activities planned. The survey was given at the end of each workshop, so those who could not attend the session for the whole day missed the opportunity to express their opinion. Finally, there are data missing from the 2007 workshops because due to technical problems, the survey could not be given at the end of the day.

It remains to be seen whether an experience like this can actually transform practices (which should be the ultimate goal of any training program, beyond improving the discourse). Also, it is worth asking to what extent the audience perceives some of the underlying messages related to new learning and teaching perspectives.

\section{Final Thoughts}

The EduCamps have served as a testing ground for the exploration of ideas concerning the design of learning environments. The results suggest the experience has an important impact on the perception of attendees about technology and its possibilities as a learning tool, but there are questions that remain open.

One area for further research is how the connections established through the EduCamps continue to develop over time and what the impact of the experience is on the educational practices of the participants in the medium and long term. Measuring changes in the participants' daily educational practices would be the truest measure of the success of the EduCamp workshops and would confirm whether the methodology (or parts of it) can be used in formal environments.

Even though there are some online spaces available, there has not been an explicit effort to bring participants into them. There is an ongoing discussion about the desirability of a centralized 
discussion/meeting area, considering that it may be secondary to the emergence of such distributed spaces as a result of an EduCamp workshop. Participants have created their own spaces on platforms such as Facebook and Ning during and after the workshops, so the experience could be aimed just to trigger these processes without attempting to centralize them in a single location. Yet, there has not been any monitoring activity to confirm whether participants keep in touch after the workshops using these spaces, and the activity in the public wiki remains very low.

It is clear that the workshops have the potential to be a trigger for the development of a community of practice around the social software platforms explored, which helps participants to sustain and enhance the connections they create during the workshop. However, this potential currently remains unrealized.

Even though the methodology has been tested with good results, there is room to explore new possibilities of application, both in face-to-face and online settings. There are also opportunities of application in subjects other than social software, including the use of mobile devices, for example.

The impact of this work goes beyond the face-to-face classroom because the design of new online learning experiences going beyond the LMS depends on teachers who have adopted some of these social software tools in their personal and professional practice. The ongoing challenge is to transcend the discourse and make it real, offering concrete examples of the potential that technology may have not only in our educational institutions, but also in our family, community, and professional environments. 


\section{References}

Anderson, T. (2007, January 27). Personalized Learning Systems and You. Presented at the Personal Learning Environments Symposium, University of Manitoba. Retrieved from http://www.umanitoba.ca/learning_technologies/plesymposium/

Attwell, G. (2007, August). e-Learning 2.0 and quality. Presented at the Seminario Internacional "Calidad en e-Learning: Estado del Arte y Perspectivas." Retrieved from http://blip.tv/file/328583

Bandura, A. (1986). Social foundations of thought and action: A social cognitive theory. Englewood Cliffs, NJ: Prentice Hall.

Benavides, F., \& Pedró, F. (2007). Políticas educativas sobre nuevas tecnologías en los países iberoamericanos. Revista Iberoamericana de Educación, 1(45). Retrieved from http://www.rieoei.org/rie45a01.htm

Brown, J., \& Isaacs, D. (2005). The World Café: Shaping our futures through conversations that matter (1st ed.). Berrett-Koehler Publishers.

Cormier, D. (2008). Rhizomatic education: Community as curriculum. Innovate, 4(5). Retrieved from http://innovateonline.info/pdf/vol4_issue5/Rhizomatic_Education_Community_as_Curriculum.pdf

Downes, S. (2005, October). E-learning 2.0. eLearn Magazine, 2005(10). Retrieved from http://www.elearnmag.org/subpage.cfm?section=articles\&article=29-1

Downes, S. (2006, October 16). Learning networks and connective knowledge. Retrieved from http://it.coe.uga.edu/itforum/paper92/paper92.html

e-Framework. (2005, November). Personal learning environments. Retrieved from http://www.eframework.org/Default.aspx?tabid=759

Gray, L. (2009, May 22). Developing personal learning networks. Retrieved from http://www.slideshare.net/elemenous/wemta-pln-workshop-lucy-gray

Hand, T. (2007). PLE - learner in digital knowledge space. Retrieved from http://thand.files.wordpress.com/2007/05/mind-map-3.jpg

Harmelen, M. V. (2006, March). Personal learning environments - JITT. Wiki. Retrieved from http://octette.cs.man.ac.uk/jitt/index.php/Personal_Learning_Environments

Leal, D. (2010). Aprendizaje en un mundo conectado: Cuando participar (y aprender) es "hacer click." In A. Piscitelli (Ed.), El Proyecto Facebook y la posuniversidad: Sistemas 
operativos sociales y entornos abiertos de aprendizaje (pp. 163-182). Madrid: Editorial Ariel / Fundación Telefónica. Retrieved from http://www.fundacion.telefonica.com/debateyconocimiento/eventos/eventos/2010/mayo/ pdf/EVEN_DYC_ESP_El\%20proyecto\%20Facebook_y_la_posuniversidad_07_05_10.p df

Leslie, S. (2008a, June 2). PLE diagrams. EdTechPost. Wiki. Retrieved from http://edtechpost.wikispaces.com/PLE+Diagrams

Leslie, S. (2008b, June 18). Revised PLE images collection \& my own PLE illustration at EdTechPost. EdTechPost. Retrieved from http://www.edtechpost.ca/wordpress/2008/06/18/my-ple-diagram/

Leslie, S. (2008c, November 6). PLE Workshop/mashing up your PLE session. EdTechPost. Retrieved from http://www.edtechpost.ca/wordpress/2008/11/06/wcet-ple-workshop-2/

Siemens, G. (2004, December 12). Connectivism: A learning theory for the digital age. Retrieved from http://www.elearnspace.org/Articles/connectivism.htm

Siemens, G. (2006). Knowing knowledge. Retrieved from http://www.elearnspace.org/KnowingKnowledge_LowRes.pdf

Trafford, P. (2006, June 3). PLEs - what are they? Exploring possible concepts and meanings. Message posted http://ramble.oucs.ox.ac.uk/blog/pault/2006/06/03/1149374141340.html

Waters, S. (2008, November 28). PLN yourself. Wiki. Retrieved from http://suewaters.wikispaces.com/page/diff/home/48476673

White, N. (2007, September 13). Learning over each other's shoulders. Full Circle Associates. Message posted to http://www.fullcirc.com/weblog/2007/09/learning-over-each-othersshoulders.htm

Wikipedia contributors. (2009). History of personal learning environments. In Wikipedia, The Free Encyclopedia. Retrieved from http://en.wikipedia.org/w/index.php?title=History_of_personal_learning_environments\& oldid=324458123

Wilson, S. (2005, January 25). Future VLE - The visual version. Message posted to http://zope.cetis.ac.uk/members/scott/blogview?entry=20050125170206

Wilson, S., Liber, O., Johnson, M., Beauvoir, P., Sharples, P., \& Milligan, C. (2007). Personal learning environments: Challenging the dominant design of educational systems. Journal of e-Learning and Knowledge Society, 3(2). Retrieved from 
http://citeseerx.ist.psu.edu/viewdoc/download?doi=10.1.1.107.3816\&rep=rep1\&type=pdf

\section{Athabasca University $\mathbf{A}$}

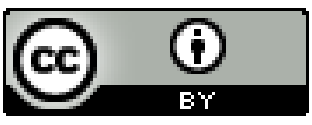

